Fixed Point Theory, 22(2021), No. 1, 299-314

DOI: $10.24193 /$ fpt-ro.2021.1.21

http://www.math.ubbcluj.ro/ nodeacj/sfptcj.html

\title{
GENERALIZED LERAY-SCHAUDER NONLINEAR ALTERNATIVES FOR GENERAL CLASSES OF MAPS
}

\author{
DONAL O'REGAN
}

School of Mathematics, Statistics and Applied Mathematics

National University of Ireland, Galway, Ireland

Abstract. New Leray-Schauder nonlinear alternatives are presented. These coincidence type results are established for set-valued maps.

Key Words and Phrases: Coincidence points, nonlinear alternatives.

2020 Mathematics Subject Classification: 54C60, 55M20, 47H10, 54H25.

\section{REFERENCES}

[1] A. Ben Amar, D. O'Regan, Topological Fixed Point Theory for Singlevalued and Multivalued Mappings with Applications, Springer, Cham, 2016.

[2] X.P. Ding, W.K. Kim, K.K. Tan, A selection theorem and its applications, Bull. Austral. Math. Soc., 46(1992), 205-212.

[3] G. Fournier, A. Granas, The Lefschetz fixed point theorem for some classes on non-metrizable spaces, J. Math. Pures Appl., 52(1973), 271-283.

[4] M. Furi, P. Pera, A continuation method on locally convex spaces and applications to ordinary differential equations on noncompact intervals, Annales Polonici Mathematici, 47(1987), 331346.

[5] A. Granas, J. Dugundji, Fixed Point Theory, Springer-Verlag, New York, 2003.

[6] D. O'Regan, Nonlinear alternatives for multivalued maps with applications to operator inclusions in abstract spaces, Proc. Amer. Math. Soc., 127(1999), 3557-3564.

[7] D. O'Regan, Furi-Pera type theorems for the $U_{c}^{\kappa}$-admissible maps of Park, Math. Proc. R. Ir. Acad., 102A(2002), 163-173.

[8] D. O'Regan, A nonlinear alternative for maps with continuous selections, Communications in Applied Analysis, 16(2012), 175-178.

[9] D. O'Regan, R. Precup, Fixed point theorems for set-valued maps and existence principles for integral inclusions, J. Math. Anal. Appl., 245(2000), 594-612.

Received: May 16, 2018; Accepted: July 15, 2018. 
DONAL O'REGAN 